\title{
Fluid responsiveness in acute circulatory failure
}

\author{
Ahmed Hasanin
}

\begin{abstract}
Although fluid resuscitation of patients having acute circulatory failure is essential, avoiding unnecessary administration of fluids in these patients is also important. Fluid responsiveness (FR) is defined as the ability of the left ventricle to increase its stroke volume (SV) in response to fluid administration. The objective of this review is to provide the recent advances in the detection of FR and simplify the physiological basis, advantages, disadvantages, and cut-off values for each method. This review also highlights the present gaps in literature and provides future thoughts in the field of FR. Static methods are generally not recommended for the assessment of FR. Dynamic methods for the assessment of FR depend on heart-lung interactions. Pulse pressure variation (PPV) and stroke volume variation (SW) are the most famous dynamic measures. Less-invasive dynamic parameters include plethysmographic-derived parameters, variation in blood flow in large arteries, and variation in the diameters of central veins. Dynamic methods for the assessment of FR have many limitations; the most important limitation is spontaneous breathing activity.

Fluid challenge techniques were able to overcome most of the limitations of the dynamic methods. Passive leg raising is the most popular fluid challenge method. More simple techniques have been recently introduced such as the mini-fluid challenge and 10-s fluid challenge. The main limitation of fluid challenge techniques is the need to trace the effect of the fluid challenges on SV (or any of its derivatives) using a real-time monitor. More research is needed in the field of FR taking into consideration not only the accuracy of the method but also the ease of implementation, the applicability on a wider range of patients, the time needed to apply each method, and the feasibility of its application by acute care physicians with moderate and low experience.
\end{abstract}

Keywords: Fluid responsiveness, Acute circulatory failure, Heart-lung interaction, Fluid challenge

\section{Introduction}

Fluid resuscitation is the cornerstone of managing patients having acute circulatory failure. Although restoring the volume status of a shocked patient is substantial, growing evidence indicates that unnecessary administration of fluids has a deleterious outcome [1].

Fluid responsiveness (FR) is defined as the ability of the left ventricle to increase its stroke volume (SV) in response to fluid administration [2]. Assessment of patient response to volume expansion presents a daily challenge for acute care physicians. FR has been extensively evaluated in various situations with acute circulatory failure

Correspondence: ahmedmohamedhasanin@gmail.com

Department of Anesthesia and Critical Care Medicine, Cairo University, Giza, Egypt

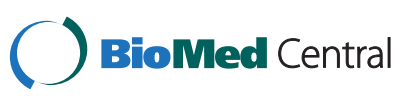

(c) 2015 Hasanin. Open Access This article is distributed under the terms of the Creative Commons Attribution 4.0 International License (http://creativecommons.org/licenses/by/4.0/, which permits unrestricted use, distribution, and reproduction in any medium, provided you give appropriate credit to the original author(s) and the source, provide a link to the Creative Commons license, and indicate if changes were made. The Creative Commons Public Domain Dedication waiver (http://creativecommons.org/publicdomain/zero/1.0/) applies to the data made available in this article, unless otherwise stated. 


\section{Review}

Static measures to assess FR Measures

Pressures Both central venous pressure (CVP) and pulmonary artery occlusion pressure (PAOP) were reported to be of a poor value in prediction of FR in both spontaneously breathing [3] and mechanically ventilated patients [4-6].

Areas and volumes Although they were considered to be good indicators of preload [7], cardiac dimensions (left ventricular end diastolic area (LVEDA) and left ventricular end diastolic volumes (LVEDV)) were reported as poor predictors of FR $[3,6,8]$.

Diameters Inferior vena cava (IVC) maximum diameter (measured by ultrasound at the subcostal area) $[9,10]$ and vascular pedicle width (measured from chest X-ray) [11, 12] have gained popularity in the assessment of volume status. Moderate evidence is available suggesting that IVC diameter is lower in hypovolemic patients $[9,10]$. The role of vascular pedicle width is more evident in patients with volume overload $[12,13]$. There is no evidence suggesting the role of absolute IVC diameter or vascular pedicle width in the prediction of FR in shocked patients.

\section{Limitations of static methods}

Many reasons described why static parameters are of poor value in the prediction of FR. First, cardiac filling pressures represent intramural pressure; however, preload is determined by transmural pressure, which is affected by both intramural and extramural pressures [14]. Second, preload alone cannot predict FR because the response of a patient to fluids depends on both preload and cardiac contractility that varies between patients. Preload will predict FR only in cases with normal ventricular contractility [15].

\section{Dynamic measures to assess FR \\ Physiological basis}

FR is detected by inducing a change in the preload and subsequently monitoring the corresponding change in SV or one of its derivatives. This change in preload is achieved in dynamic measures by positive pressure ventilation. Positive pressure ventilation provokes a cyclic decrease in the right ventricular (RV) SV via two mechanisms:

1. Decreased preload (decreased venous return)

2. Increased afterload (increased transpulmonary pressure) [16].
RV stroke volume reaches its minimum value by the end of inspiration resulting in a consequent decrease in LV filling and thus LV stroke volume after a lag period of 2-3 heartbeats $[17,18]$.

Two other mechanisms were mentioned to antagonize the negative effect of mechanical ventilation on SV:

1. Squeezing of blood out of alveolar vessels and thus transiently increasing LV preload [19]

2. Inspiratory increase in pleural pressure that decreases LV afterload, enhancing LV ejection

However, experimental data suggest that the latter two mechanisms have a minor effect on LV stroke volume. Consequently, the net effect of positive pressure ventilation is decreasing RV stroke volume, LV filling, and LV stroke volume [16]. This decrease in SV is more prominent when the patient is on the steep part of cardiac contractility "Frank-Starling" curve (fluid responder).

\section{Measures}

Systolic pressure variation (SPV) SPV is calculated by measuring the difference between both the maximal and the minimal values of systolic blood pressure (SBP) during a single respiratory cycle and a reference value (reference value is SBP measured at end expiratory pause) [16]. SPV was reported to increase with induction of hypovolemia in mechanically ventilated dogs [20], mechanically ventilated patients after aortic surgery [21], and patients with septic shock [22]. Denault et al. [23] reported SPV to be affected by airway and pleural pressures rather than volume status; however, a metaanalysis conducted by Marik et al. showed area under receiver operating characteristics (AUROC) $=0.86$ for SPV for the detection of FR [6].

Pulse pressure variation (PPV) PPV is calculated by dividing the largest $\mathrm{PP}\left(\mathrm{PP}_{\max }-\mathrm{PP}_{\min }\right)$ by the average $\mathrm{PP}$ $\left(\mathrm{PP}_{\max }+\mathrm{PP}_{\min } / 2\right) . \mathrm{PPV}$ above $13 \%$ [24] is a good predictor of FR [25] [6]. AUROC was reported as 0.98 in a prospective cohort study [26] and 0.94 in a meta-analysis [6]. PPV has an advantage over SPV of not being affected by airway and pleural pressure because these pressures affect both SBP and diastolic blood pressure (DBP), whereby the PP (difference between SBP and DBP) remains unaffected [27]. In the intraoperative situation, PPV showed low accuracy with patients undergoing gastrointestinal (GIT) surgery [28]. PPV was accurate after cardiac surgery only when patients with low perfusion or right ventricular dysfunction were excluded [29].

Stroke volume variation ( $S V V$ ) SVV is commonly measured by $\mathrm{PiCCO}$ continuous cardiac output monitoring 
[30] or esophageal Doppler [31, 32]. It is calculated by dividing the difference between maximum $\mathrm{SV}$ and minimum $\mathrm{SV}\left(\mathrm{SV}_{\max }-\mathrm{SV}_{\min }\right)$ by their average $\left(\mathrm{SV}_{\max }+\right.$ $\left.\mathrm{SV}_{\min } / 2\right)$ in a time window of $30 \mathrm{~s}$. SVV was reported as a good predictor of FR in brain surgery patients [30], general surgical patients [32], septic shock patients [33], and after cardiac surgery [34]. SVV was not accurate with patients undergoing GIT surgery [28]. A recent meta-analysis reported SVV as a reliable predictor for FR in mechanically ventilated patients on tidal volume above $8 \mathrm{ml} / \mathrm{kg}$ with AUROC 0.84 [6]. The proper cut-off value was $14 \%$ for SVV $[32,35]$ and $11 \%$ for stroke output index [31].

Plethysmographic dynamic indices Pulse oximetry plethysmographic waveform amplitude (POP) is measured using a special pulse oximetry sensor; plethysmographic variability index (PVI) is more easily measured using Masimo device. Both POP and PVI were reported in a recent meta-analysis as good indicators for FR in mechanically ventilated patients without cardiac arrhythmias, heart failure, or spontaneous activity with cut-off value 9.1-15\% [36]. PVI measured before induction of anesthesia predicted propofol-induced hypotension during induction of anesthesia [37]. PVI showed low accuracy in the detection of FR after cardiac surgery [29].

IVC respiratory variation IVC variation is best assessed using ultrasound in the long-axis (sagittal) view. IVC diameter is measured $1 \mathrm{~cm}$ distal to its junction with hepatic vein either by 2-D or M modes [38]. Although data about IVC variation in FR are heterogeneous with regard to the type of patients, type of fluid, and definition of collapsibility index, there is a consensus that a cut-off value of $12-21 \%$ for IVC variation is useful in the detection of FR in mechanically ventilated patients $[39,40]$. In spontaneously breathing patients, a more cautious use was suggested by Muller and coworkers who reported IVC variability $>40 \%$ to predict FR. They also suggested that low values $(<40 \%)$ do not exclude FR [41].

SVC respiratory variation SVC variation (measured using TEE) predicts FR with a cut-off value that ranged between 29 [40] and $36 \%$ [42]. Variation in the peak flow velocity in SVC predicts FR at a cut-off value of $12.7 \%[43]$.

\section{Internal jugular vein (IJV) and subclavian vein} respiratory variation IJV distensibility measured using ultrasound was recently reported as a predictor of FR in mechanically ventilated patients with cut-off value $18 \%$. The combination of IJV distensibility of $9.7 \%$ and PPV more than $12 \%$ reaches a sensitivity of $100 \%$ and specificity of $95 \%$ [44]. A recent study reported IJV collapsibility index to overestimate the collapsibility when compared with IVC; they also reported a weak correlation between IJV and IVC collapsibility, raising a controversy about IJV use in the prediction of FR [45]. Subclavian vein collapsibility was also reported as an alternative method to detect FR with the advantage of having easy and fast access than IVC [46].

Subaortic velocity time integral (VTI) variation Subaortic VTI variation was reported by Slama et al. as a predictor for FR in experimental animals [47]. However, it has not been tried in humans yet.

Aortic velocity variation Respiratory variation of peak aortic velocity was reported as a good indicator for FR in critically ill patients under mechanical ventilation: the best cut-off value was $18 \%$ when measured by esophageal Doppler [48] and $12 \%$ when measured by trans-esophageal echocardiography [49]. In a study conducted by Guinot et al., peak aortic velocity measured by esophageal Doppler did not predict FR during surgery [32].

\section{Carotid artery peak velocity variation}

Carotid artery peak velocity variation measured using ultrasound was recently reported in two observational studies to predict FR in patients undergoing coronary artery bypass grafting (CABG) surgery [50] as well as patients with septic shock [51] with cut-off values 11 and $14 \%$, respectively.

A comparison between different dynamic methods is presented in Table 1.

\section{Limitation of dynamic measures}

Spontaneous breathing Spontaneous breathing is the most important limitation of dynamic methods. Failure of dynamic methods in detecting FR was reported in patients with spontaneous breathing $[52,53]$ as well as patients on pressure support ventilation [54]. This was explained by the dependence of dynamic parameters on regular variations in intrathoracic pressure, tidal volume, and rate; all these components are highly variable in spontaneous breathing patients in addition to the effect of abdominal muscle contractions (which is common with spontaneous breathing efforts) on the preload response [55].

Ventilator-related causes Dynamic parameters poorly detect FR with tidal volumes below $8 \mathrm{ml} / \mathrm{kg}[56,57]$ and patients with low airway driving pressure below $20 \mathrm{~cm} /$ $\mathrm{H}_{2} \mathrm{O}$ [58]. This was explained by the fact that low tidal volume induces small variation in thoracic pressure and 
Table 1 Dynamic methods for the detection of FR

\begin{tabular}{llll}
\hline Parameter & Cut-off value (\%) & Evidence & Limitations \\
\hline SPV $[6,16,20-23]$ & NA & Cohort & Affected by airway and pleural pressure [17] \\
PPV $[6,24-29]$ & 13 & Meta-analysis & Needs special monitor; needs arterial line \\
SW $[6,30,32-35]$ & 14 & Cohort & Needs either arterial line (plus special monitor) or esophageal Doppler \\
SOI [31] & 11 & Cohort & Needs esophageal Doppler \\
POP [36] & $9.5-15$ & Meta-analysis & Needs special pulse oximeter \\
PVI [36, 37] & $9.5-15$ & Meta-analysis & Needs Masimo device \\
IVC variation [38-41] & $12-21$ & Meta-analysis & Needs ultrasound; difficult in abdominal surgical cases; \\
SVC variation [40-42] & $29-36$ & Cannot be used intraoperatively \\
IJV variation [44, 45] & 18 & Needs trans-esophageal echocardiography \\
Subaortic VTI [47] & NA & Cohort & Needs ultrasound \\
Aortic velocity variation $[48,49]$ & $12-18$ & Cohimal study & Needs echocardiography; needs good operator experience; \\
Carotid velocity variation $[50,51]$ & $11-14$ & not tried in humans yet \\
\hline SPV systic & Coeds echocardiography or esophageal Doppler
\end{tabular}

SPV systolic pressure variation, PPV pulse pressure variation, SVV stroke volume variation, SOI stroke output index, $P O P$ pulse oximetry plethysmographic waveform amplitude, PVI Plethysmographic variability index, IVC inferior vena cava, SVC superior vena cava, IJV internal jugular vein, VTI velocity time integral, NA not available

consequently small changes in preload [59]. With tidal volumes below $8 \mathrm{ml} / \mathrm{kg}$, FR is present even with lower PPV. The cut-off value for prediction of FR with low tidal volumes should be $8 \%$ and not $12 \%$ as in higher tidal volumes [56]. Failure of dynamic methods was also reported in cases with highfrequency ventilation; this is because the low number of cardiac cycles per respiratory cycle will not allow respiratory variation in SV to occur [60].

\section{Low lung compliance}

Dynamic methods for the detection of FR were reported to be of low value in cases of reduced lung compliance, especially in cases of low PPV [26, 59, 61]; however, the presence of high PPV in patients of acute respiratory distress syndrome (ARDS) is an indicator of FR when patient tidal volume is above $8 \mathrm{ml} / \mathrm{kg}$ [59].

Elevated pulmonary artery pressure PPV poorly predicted FR in patients with elevated pulmonary artery pressure. These patients usually do not respond to fluid resuscitation [62].

\section{Cardiac causes}

Dynamic measures are not valid in cases having cardiac arrhythmias [63], and variation in SV in these cases is influenced by irregular rhythm rather than heart-lung interactions. PPV was not able to predict FR in patients with elevated LV pressure (defined as E/E'> 15) [64]. Both PVV and SVV were altered by propranolol-induced acute ventricular failure in mongrel dogs [65].

Open-chest conditions Neither PPV nor SVV was able to predict FR under open-chest conditions; this was reported in patients undergoing CABG surgery during thoracotomy. Dynamic methods showed good performance in the same patient group after chest closure [66].

Intra-abdominal hypertension Increased intraabdominal pressure above $10.5 \mathrm{mmHg}$ impairs the accuracy of PPV [67].

A 1-day prospective multicenter study reported that only $2 \%$ of patients with acute circulatory failure in the ICU have fulfilled the validity criteria for valid application of PPV. This finding increases the interest in fluid challenge methods to overcome the known limitations for dynamic methods especially outside the operating room [68].

\section{Preload and fluid challenge Physiological basis}

Fluid challenge methods are done by administration of a fluid bolus (either extrinsically or intrinsically) and monitoring the resulting effect on SV or cardiac output (CO). Fluid responders are patients with $15 \%$ increase in SV or CO after fluid challenge [25]. SV and CO can be measured using transpulmonary thermodilution, pulse contour analysis [25], bioreactance [69], and echocardiography (through measuring subaortic VTI) [25]. Alternative parameters to detect patient response to passive leg raising (PLR) include the following: decreased PPV and SVV [70], increased radial pulse pressure (by $10 \%)$, femoral artery peak velocity [71], carotid artery diameter, and peak velocity [69].

Recently, indirect methods of measurement of the $\mathrm{CO}$ response to PLR were introduced. Those include endtidal $\mathrm{CO}_{2}$ (5\% increase) [72], mixed venous oxygen 
saturation ( $2 \%$ increase) [73], sublingual microcirculatory perfusion, and skin perfusion [74].

\section{Measures}

Passive leg raising PLR creates a transient increase in the preload via translocation of venous blood from the lower limbs to the thorax. It has been described as an attractive method of fluid challenge having the advantage of being a "self-volume challenge" and a "reversible fluid challenge" [53]. PLR-induced increase in SV (or its derivatives) can determine FR in most situations that dynamic methods fail to deal with such as spontaneous breathing, decreased respiratory compliance, and cardiac arrhythmias $[26,75]$. The best cut-off value for detecting FR is increased in aortic blood flow by $10 \%$ (using esophageal Doppler) [53] or increased cardiac index by $10 \%$ (using thermodilution) [26] after PLR.

End expiratory occlusion EEO is done by interrupting mechanical ventilation at the end expiratory pause for $15 \mathrm{~s}$ with monitoring SV or its derivatives [76]. EEO is considered another method for "self-fluid challenge" as it attenuates the inspiratory increase in thoracic pressure resulting in increasing the venous return [76]. EEOinduced increase in $\mathrm{CO}$ by $5 \%$ was reported to predict FR in most patients in whom dynamic measures fail such as patients with arrhythmias [76], decreased respiratory compliance [26], and ARDS patients [77]. EEO can be used in patients with spontaneous breathing activity unless excessive triggering results into test interruption [78].

EEO showed the same accuracy as PLR when the response to both of them was assessed using cardiac index. EEO was superior to PLR if the response was assessed by changes in arterial pulse pressure; this was explained by PLR-induced change in arterial compliance, which impairs the ability of arterial pulse pressure to reflect the changes in SV with PLR [76]. However, PLR has the advantage over EEO in being applicable in non-intubated patients [76]. Although Guinot et al. reported a poor value for EEO in the prediction of FR in the operating theater, this finding was reported in operated patients with no signs of shock [79].

PEEP-induced hemodynamic changes Increasing PEEP by $10 \mathrm{~cm} \mathrm{H}_{2} \mathrm{O}$ produces a hemodynamic effect that is near to EEO. Geerts et al. reported that FR can be predicted in cardiac surgery patients if increasing PEEP by $10 \mathrm{~cm} \mathrm{H}_{2} \mathrm{O}$ for 5 min produced an increase in CVP with AUROC $=0.99$; however, no data is available about the cut-off value of the change in CVP that would predict FR [80]. This method has an advantage over EEO of not being affected by ventilator conditions, easily done in ICU patients with no need for any advanced monitors.

Another method for the detection of FR was reported by Wilkman et al. in patients with septic shock by increasing PEEP from 10 to $20 \mathrm{~cm} \mathrm{H}_{2} \mathrm{O}$ and following their MAP. A negative predictive value was $100 \%$, so the absence of decrease of MAP during PEEP elevation can identify non-responders [81].

Arm occlusion pressure Arm occlusion pressure is defined as "the radial artery pressure after $35 \mathrm{~s}$ occlusion by a blood pressure cuff"; it is measured using an arterial catheter. Arm occlusion pressure is considered as an indicator of mean filling pressure and volume status of the upper limb. Arm occlusion pressure less than $21.9 \mathrm{mmHg}$ detected FR in cardiac surgery patients [82].

Mini-fluid challenge Mini-fluid challenge is performed by infusing $100 \mathrm{ml}$ colloids over $1 \mathrm{~min}$ with concomitant monitoring of aortic VTI. An increase in VTI by $10 \%$ after mini-fluid challenge predicts FR [83].

Ten-second fluid challenge Infusion of $50 \mathrm{ml}$ crystalloids with monitoring of $\mathrm{CO}$ or SV was recently reported as a method for the detection of FR. The best cut-off value was $9 \%$ increase in $\mathrm{CO}$ or SV after fluid administration [84].

Table 2 Fluid challenge methods for the detection of FR

\begin{tabular}{llll}
\hline Parameter & Cut-off value & Evidence & Limitations \\
\hline PLR [26, 53, 75] & $10 \%$ increase in aortic flow or Cl & Meta-analysis & $\begin{array}{l}\text { Not feasible in intraoperative situations and some surgical } \\
\text { patients; needs CO monitoring }\end{array}$ \\
EEO [26, 76-79] & $5 \%$ increase in CO & Cohort & Needs MV; needs CO monitoring \\
PEEP-induced increase in CVP [80] & $1.5 \mathrm{mmHg}$ & Cohort & Tried only in cardiac surgery patients \\
PEEP-induced decrease in MAP [81] & $\mathrm{NA}$ & Cohort & Useful only in identifying non-responders \\
Arm occlusion pressure [82] & $21.9 \mathrm{mmHg}$ & Cohort & Tried only in cardiac surgery patients \\
Mini-fluid challenge [83] & $10 \%$ increase in subaortic VTI & Cohort & Needs echocardiography with experienced operator \\
10-s fluid challenge [84] & $9 \%$ increase in CO or SV & Cohort & Needs CO or SV monitoring \\
\hline
\end{tabular}

$P L R$ passive leg raising, EEO end expiratory occlusion, PEEP positive end expiratory pressure, $C V P$ central venous pressure, MAP mean arterial pressure, $C O$ cardiac output, $C I$ cardiac index, SV stroke volume, BP blood pressure, VTI velocity time integral, NA not available 
A comparison between different methods for fluid challenge is described in Table 2.

\section{Limitations of fluid challenge techniques}

The main limitation in using fluid challenge methods for the detection of FR is the need for real-time monitoring of $\mathrm{SV}$ or $\mathrm{CO}$ to differentiate fluid responders. Alternative less-invasive parameters are being introduced to trace patient response to PLR such as end-tidal $\mathrm{CO}_{2}$ [72] and peak velocity in different arteries measured by ultrasound $[69,71]$.

\section{Effect of vasopressors on different methods for the detection of FR}

Norepinephrine infusion decreases PPV and SVV, masking their ability for the detection of FR. This finding was addressed in two experimental animal studies on dogs [85] and pigs [86]. Moreover, measurement of SV using FloTrac/Vigileo System is not accurate under conditions with increased vasomotor tone due to phenylephrine infusion [87]. On the contrary, the PLR test kept its value as a predictor of FR in patients with septic shock even after increasing norepinephrine dose [88].

\section{Present gaps in the literature}

Four problems with FR still need to be solved:

1. Most of the dynamic methods for the detection of FR need invasive monitoring by an arterial line (except plethysmographic indices and ultrasound indices); less-invasive methods are needed.

2. Most of the fluid challenge techniques need realtime SV monitoring (or VTI monitoring using echocardiography); more simple monitors are needed.

3. Methods suitable for intraoperative use are still limited.

4. The ease of application for any method by a nonexpert physician should be considered.

\section{Conclusions}

Static methods are generally not recommended for the detection of FR. Dynamic methods rely on heart-lung interactions. Dynamic methods are accurate and reliable; however, these measures are useful in few selected types of patients. PPV and SVV are the most popular dynamic methods. Further research is needed for introducing less-invasive dynamic methods with fewer limitations.

Fluid challenge methods were able to overcome most of the limitations of dynamic methods; however, these methods need a real-time monitoring for SV or one of its derivatives. PLR is considered to be the standard method for fluid challenge. Recent publications described more simple methods (e.g., 10-s fluid challenge, carotid artery peak velocity variation). These new methods still need more validation in different types of patients. Validation is also needed for more simple methods for tracing SV response to fluids.

Comparing various methods for the detection of FR should take into consideration not only the accuracy of the method but also the ease of implementation, the applicability on a wider range of patients, the time needed to apply each method, and the feasibility of its application by acute care physicians with moderate and low experience.

\section{Abbreviations}

ABP: arterial blood pressure; ARDS: acute respiratory distress syndrome; AUROC: area under receiver operating characteristics; CABG: coronary artery bypass grafting; $\mathrm{CO}$ : cardiac output; $\mathrm{CO}_{2}$ : carbon dioxide; CVP: central venous pressure; DBP: diastolic blood pressure; EEO: end expiratory occlusion; FR: fluid responsiveness; ICU: intensive care unit; IVC: inferior vena cava; LV: left ventricular; LVEDA: left ventricular end diastolic area; LVEDV: left ventricular end diastolic volumes; MAP: mean arterial pressure; PAOP: pulmonary artery occlusion pressure; PEEP: positive end expiratory pressure; PLR: passive leg raising; POP: pulse oximetry plethysmographic waveform amplitude; PPV: pulse pressure variation; PVI: plethysmographic variability index; RV: right ventricular; SBP: systolic blood pressure;

SPV: systolic pressure variation; SV: stroke volume; SVC: superior vena cava; $\mathrm{SVO}_{2}$ : ventral venous oxygen saturation; $\mathrm{SW}$ : stroke volume variation; TEE: trans-esophageal echocardiography; TTE: trans-thoracic echocardiography; VTI: velocity time integral.

\section{Competing interests}

The author declares that he has no competing interests.

\section{Acknowledgements}

I would like to thank Dr Ahmed Mukhtar, professor of Anesthesia and Critical Care Medicine, and Dr Amr Kamal, assistant lecturer of Anesthesia and Critical Care Medicine, for their kind help in writing this article.

Received: 29 July 2015 Accepted: 16 November 2015

Published online: 19 November 2015

\section{References}

1. Vincent J-L, Sakr Y, Sprung CL, Ranieri VM, Reinhart K, Gerlach H, et al. Sepsis in European intensive care units: results of the SOAP study. Crit Care Med. 2006;34:344-53.

2. Huang C-C, Fu J-Y, Hu H-C, Kao K-C, Chen N-H, Hsieh M-J, et al. Prediction of fluid responsiveness in acute respiratory distress syndrome patients ventilated with low tidal volume and high positive end-expiratory pressure. Crit Care Med. 2008;36:2810-6.

3. Coudray A, Romand J-A, Treggiari M, Bendjelid K. Fluid responsiveness in spontaneously breathing patients: a review of indexes used in intensive care. Crit Care Med. 2005;33:2757-62.

4. Osman D, Ridel C, Ray P, Monnet X, Anguel N, Richard C, et al. Cardiac filling pressures are not appropriate to predict hemodynamic response to volume challenge. Crit Care Med. 2007;35:64-8.

5. Marik PE, Cavallazzi R. Does the central venous pressure predict fluid responsiveness? An updated meta-analysis and a plea for some common sense. Crit Care Med. 2013;41:1774-81.

6. Marik PE, Cavallazzi R, Vasu T, Hirani A. Dynamic changes in arterial waveform derived variables and fluid responsiveness in mechanically ventilated patients: a systematic review of the literature. Crit Care Med. 2009;37:2642-7.

7. Kumar A, Anel R, Bunnell E, Habet K, Zanotti S, Marshall S, et al. Pulmonary artery occlusion pressure and central venous pressure fail to predict ventricular filling volume, cardiac performance, or the response to volume infusion in normal subjects. Crit Care Med. 2004;32:691-9.

8. Lamia B, Ochagavia A, Monnet X, Chemla D, Richard C, Teboul J-L. Echocardiographic prediction of volume responsiveness in critically ill patients with spontaneously breathing activity. Intensive Care Med. 2007;33:1125-32 
9. Dipti A, Soucy Z, Surana A, Chandra S. Role of inferior vena cava diameter in assessment of volume status: a meta-analysis. Am J Emerg Med. 2012;30:1414-9.

10. Zengin S, Al B, Genc S, Yildirim C, Ercan S, Dogan M, et al. Role of inferior vena cava and right ventricular diameter in assessment of volume status: a comparative study: ultrasound and hypovolemia. Am J Emerg Med. 2013;31:763-7.

11. Miller RR, Ely EW. Radiographic measures of intravascular volume status: the role of vascular pedicle width. Curr Opin Crit Care. 2006;12:255-62.

12. Wichansawakul S, Vilaichone W, Tongyoo S, Permpikul C, Wonglaksanapimol S, Daengnim K, et al. Evaluation of correlation between vascular pedicle width and intravascular volume status in Thai critically ill patients. J Med Assoc Thai. 2011;94 Suppl 1:S181-7.

13. Wang H, Shi R, Mahler S, Gaspard J, Gorchynski J, D’Etienne J, et al. Vascular pedicle width on chest radiograph as a measure of volume overload: meta-analysis. West J Emerg Med. 2011;12:426-32.

14. Cherpanath TG V, Lagrand WK, Schultz MJ, Groeneveld ABJ. Cardiopulmonary interactions during mechanical ventilation in critically ill patients. Netherlands Hear J. 2013;21:166-72.

15. Braunwald E, Sonnenblick EH RJ. Mechanisms of cardiac contraction and relaxation. In: Braunwald E, editor. heart disease. Philadelphia: Saunders; 1998. p. 389-425.

16. Michard F, Teboul JL. Using heart-lung interactions to assess fluid responsiveness during mechanical ventilation. Crit Care. 2000;4:282-9.

17. Jardin F, Farcot JC, Gueret P, Prost JF, Ozier Y, Bourdarias JP. Cyclic changes in arterial pulse during respiratory support. Circulation. 1983;68:266-74.

18. Scharf SM, Brown R, Saunders N, Green LH. Hemodynamic effects of positive-pressure inflation. J Appl Physiol. 1980;49:124-31.

19. Brower R, Wise RA, Hassapoyannes C, Bromberger-Barnea B, Permutt S. Effect of lung inflation on lung blood volume and pulmonary venous flow. J Appl Physiol. 1985;58:954-63.

20. Perel A, Pizov R, Cotev S. Systolic blood pressure variation is a sensitive indicator of hypovolemia in ventilated dogs subjected to graded hemorrhage. Anesthesiology. 1987;67:498-502.

21. Coriat P, Vrillon M, Perel A, Baron JF, Le Bret F, Saada M, et al. A comparison of systolic blood pressure variations and echocardiographic estimates of end-diastolic left ventricular size in patients after aortic surgery. Anesth Analg. 1994;78:46-53.

22. Tavernier B, Makhotine O, Lebuffe G, Dupont J, Scherpereel P. Systolic pressure variation as a guide to fluid therapy in patients with sepsisinduced hypotension. Anesthesiology. 1998;89:1313-21.

23. Denault AY, Gasior TA, Gorcsan J, Mandarino WA, Deneault LG, Pinsky MR. Determinants of aortic pressure variation during positive-pressure ventilation in man. Chest. 1999;116:176-86.

24. Goarin JP, Lehot J, Ph D, Vallet B, Tavernier B. Assessing the diagnostic accuracy of pulse pressure. Anesthesiology. 2011;89:231-41.

25. Yang $X$, Du B. Does pulse pressure variation predict fluid responsiveness in critically ill patients? A systematic review and meta-analysis. Crit Care. 2014;18:650.

26. Monnet X, Bleibtreu A, Ferré A, Dres M, Gharbi R, Richard C, et al. Passive leg-raising and end-expiratory occlusion tests perform better than pulse pressure variation in patients with low respiratory system compliance. Crit Care Med. 2012;40:152-7.

27. Theres $\mathrm{H}$, Binkau J, Laule M, Heinze R, Hundertmark J, Blobner M, et al. Phase-related changes in right ventricular cardiac output under volumecontrolled mechanical ventilation with positive end-expiratory pressure. Crit Care Med. 1999;27:953-8.

28. MacDonald N, Ahmad T, Mohr O, Kirk-Bayley J, Moppett I, Hinds CJ, et al. Dynamic preload markers to predict fluid responsiveness during and after major gastrointestinal surgery: an observational substudy of the OPTIMISE trial. Br J Anaesth. 2014;114:598-604

29. Fischer M-O, Pelissier A, Bohadana D, Gérard J-L, Hanouz J-L, Fellahi J-L. Prediction of responsiveness to an intravenous fluid challenge in patients after cardiac surgery with cardiopulmonary bypass: a comparison between arterial pulse pressure variation and digital plethysmographic variability index. J Cardiothorac Vasc Anesth. 2013;27:1087-93.

30. Berkenstadt H, Margalit N, Hadani M, Friedman Z, Segal E, Villa Y, et al. Stroke volume variation as a predictor of fluid responsiveness in patients undergoing brain surgery. Anesth Analg. 2001;92:984-9.

31. Vallée F, Fourcade O, De Soyres O, Angles O, Sanchez-Verlaan P, Pillard F, et al. Stroke output variations calculated by esophageal Doppler is a reliable predictor of fluid response. Intensive Care Med. 2005;31:1388-93.
32. Guinot PG, De Broca B, Abou Arab O, Diouf M, Badoux L, Bernard E, et al. Ability of stroke volume variation measured by oesophageal Doppler monitoring to predict fluid responsiveness during surgery. Br J Anaesth. 2013;110:28-33.

33. Khwannimit $B$, Bhurayanontachai R. Prediction of fluid responsiveness in septic shock patients: comparing stroke volume variation by FloTracNigileo and automated pulse pressure variation. Eur J Anaesthesiol. 2012;29:64-9.

34. Reuter DA, Kirchner A, Felbinger TW, Weis FC, Kilger E, Lamm P, et al. Usefulness of left ventricular stroke volume variation to assess fluid responsiveness in patients with reduced cardiac function. Crit Care Med. 2003;31:1399-404

35. Cannesson M, Tran NP, Cho M, Hatib F, Michard F. Predicting fluid responsiveness with stroke volume variation despite multiple extrasystoles. Crit Care Med. 2012:40:193-8.

36. Sandroni C, Cavallaro F, Marano C, Falcone C, De Santis P, Antonelli M. Accuracy of plethysmographic indices as predictors of fluid responsiveness in mechanically ventilated adults: a systematic review and meta-analysis. Intensive Care Med. 2012;38:1429-37.

37. Tsuchiya M, Yamada T, Asada A. Pleth variability index predicts hypotension during anesthesia induction. Acta Anaesthesiol Scand. 2010;54:596-602.

38. Evans D, Ferraioli G, Snellings J, Levitov A. Volume responsiveness in critically ill patients. J Ultrasound Med. 2014;33:3-7.

39. Zhang Z, Xu X, Ye S, Xu L. Review ultrasonographic measurement of the respiratory variation in the inferior vena cava diameter is predictive of fluid responsiveness in critically ill patients: systematic review and meta-analysis. Ultrasound Med Biol. 2014;40:845-53.

40. Charbonneau H, Riu B, Faron M, Mari A, Kurrek MM, Ruiz J, et al. Predicting preload responsiveness using simultaneous recordings of inferior and superior vena cavae diameters. Crit Care. 2014;18:473.

41. Muller L, Bobbia X, Toumi M, Louart G, Molinari N, Ragonnet B, et al. Respiratory variations of inferior vena cava diameter to predict fluid responsiveness in spontaneously breathing patients with acute circulatory failure: need for a cautious use. Crit Care. 2012;16:R188.

42. Vieillard-Baron A, Chergui K, Rabiller A, Peyrouset O, Page B, Beauchet A, et al. Superior vena caval collapsibility as a gauge of volume status in ventilated septic patients. Intensive Care Med. 2004;30:1734-9.

43. Guo Z, He W, Hou J, Li T, Zhou H, Xu Y, et al. The assessment of ultrasonic measurement of superior vena cava blood flow for the volume responsiveness of patients with mechanical ventilation. Zhonghua Wei Zhong Bing Ji Jiu Yi Xue. 2014;26:624-8.

44. Guarracino F, Ferro B, Forfori F, Bertini P, Magliacano L, Pinsky MR. Jugular vein distensibility predicts fluid responsiveness in septic patients. Crit Care. 2014;18:647.

45. Kent A, Patil P, Davila V, Bailey JK, Jones C, Evans DC, et al. Sonographic evaluation of intravascular volume status: can internal jugular or femoral vein collapsibility be used in the absence of IVC visualization? Ann Thorac Med. 2015:10:44-9.

46. Kent A, Bahner DP, Boulger CT, Eiferman DS, Adkins EJ, Evans DC, et al. Sonographic evaluation of intravascular volume status in the surgical intensive care unit: a prospective comparison of subclavian vein and inferior vena cava collapsibility index. J Surg Res. 2013;184:561-6.

47. Slama M, Masson H, Teboul J-L, Arnout M-L, Susic D, Frohlich E, et al. Respiratory variations of aortic VTI: a new index of hypovolemia and fluid responsiveness. Am J Physiol Hear Circ Physiol. 2002;283:1729-33.

48. Monnet X, Rienzo M, Osman D, Anguel N, Richard C, Pinsky MR, et al. Esophageal Doppler monitoring predicts fluid responsiveness in critically ill ventilated patients. Intensive Care Med. 2005;31:1195-201.

49. Feissel M, Michard F, Mangin I, Ruyer O, Faller JP, Teboul JL. Respiratory changes in aortic blood velocity as an indicator of fluid responsiveness in ventilated patients with septic shock. Chest. 2001;119:867-73.

50. Song Y, Kwak YL, Song JW, Kim YJ, Shim JK. Respirophasic carotid artery peak velocity variation as a predictor of fluid responsiveness in mechanically ventilated patients with coronary artery disease. $\mathrm{Br} J$ Anaesth. 2014;113:61-6.

51. Ibarra-estrada MÁ, López-pulgarín JA, Mijangos-méndez JC, Díaz-gómez JL. Respiratory variation in carotid peak systolic velocity predicts volume responsiveness in mechanically ventilated patients with septic shock: a prospective cohort study. Crit Ultrasound J. 2015;7:29.

52. Heenen S, De Backer D, Vincent J. How can the response to volume expansion in patients with spontaneous respiratory movements be predicted? Crit Care. 2006;10:R102. 
53. Monnet X, Rienzo M, Osman D, Anguel N, Richard C, Pinsky MR, et al. Passive leg raising predicts fluid responsiveness in the critically ill. Crit Care Med. 2006;34:1402-7.

54. Perner A, Faber T. Stroke volume variation does not predict fluid responsiveness in patients with septic shock on pressure support ventilation. Acta Anaesthesiol Scand. 2006;50:1068-73.

55. De Backer D, Pinsky MR. Can one predict fluid responsiveness in spontaneously breathing patients? Intensive Care Med. 2007;33:1111-3.

56. De Backer D, Heenen S, Piagnerelli M, Koch M, Vincent J-L. Pulse pressure variations to predict fluid responsiveness: influence of tidal volume. Intensive Care Med. 2005;31:517-23.

57. Charron C, Fessenmeyer C, Cosson C, Mazoit J-X, Hebert J-L, Benhamou D, et al. The influence of tidal volume on the dynamic variables of fluid responsiveness in critically ill patients. Anesth Analg. 2006;102:1511-7.

58. Muller L, Louart G, Bousquet P-J, Candela D, Zoric L, de La Coussaye J-E, et al. The influence of the airway driving pressure on pulsed pressure variation as a predictor of fluid responsiveness. Intensive Care Med. 2010;36:496-503.

59. Teboul JL, Monnet X. Pulse pressure variation and ARDS. Minerva Anestesiol. 2013;79:398-407.

60. De Backer D, Taccone FS, Holsten R, Ibrahimi F, Vincent J-L. Influence of respiratory rate on stroke volume variation in mechanically ventilated patients. Anesthesiology. 2009;110:1092-7.

61. Lefrant J-Y, De Backer D. Can we use pulse pressure variations to predict fluid responsiveness in patients with ARDS? Intensive Care Med. 2009;35: 966-8.

62. Wyler Von Ballmoos M, Takala J, Roeck M, Porta F, Tueller D, Ganter CC, et al. Pulse-pressure variation and hemodynamic response in patients with elevated pulmonary artery pressure: a clinical study. Crit Care. 2010;14:R111.

63. Cherpanath TG V, Geerts BF, Lagrand WK, Schultz MJ, Groeneveld ABJ. Basic concepts of fluid responsiveness. Neth Heart J. 2013;21:530-6.

64. Shim J-K, Song J-W, Song Y, Kim J-H, Kang H-M, Kwak Y-L. Pulse pressure variation is not a valid predictor of fluid responsiveness in patients with elevated left ventricular filling pressure. J Crit Care. 2014;29:987-91.

65. Mesquida J, Kim HK, Pinsky MR. Effect of tidal volume, intrathoracic pressure, and cardiac contractility on variations in pulse pressure, stroke volume, and intrathoracic blood volume. Intensive Care Med. 2011;37:1672-9.

66. De Waal EEC, Rex S, Kruitwagen CLJJ, Kalkman CJ, Buhre WF. Dynamic preload indicators fail to predict fluid responsiveness in open-chest conditions. Crit Care Med. 2009;37:510-5.

67. Royer P, Bendjelid K, Valentino R, Résière D, Chabartier C, Mehdaoui H. Influence of intra-abdominal pressure on the specificity of pulse pressure variations to predict fluid responsiveness. J Trauma Acute Care Surg. 2015:78:994-9.

68. Mahjoub Y, Lejeune V, Muller L, Perbet S, Zieleskiewicz L, Bart F, et al. Evaluation of pulse pressure variation validity criteria in critically ill patients: a prospective observational multicentre point-prevalence study. $\mathrm{Br} J$ Anaesth. 2014;112:681-5.

69. Marik PE, Levitov A, Young A, Andrews L. The use of bioreactance and carotid Doppler to determine volume responsiveness and blood flow redistribution following passive leg raising in hemodynamically unstable patients. Chest. 2013;143:364-70.

70. Mallat J, Meddour M, Durville E, Lemyze M, Pepy F, Temime J, et al. Decrease in pulse pressure and stroke volume variations after mini-fluid challenge accurately predicts fluid responsiveness. $\mathrm{Br} J$ Anaesth. 2015;115:449-56.

71. Préau S, Saulnier F, Dewavrin F, Durocher A, Chagnon J-L. Passive leg raising is predictive of fluid responsiveness in spontaneously breathing patients with severe sepsis or acute pancreatitis. Crit Care Med. 2010;38:819-25.

72. Monnet X, Bataille A, Magalhaes E, Barrois J, Le Corre M, Gosset C, et al. End-tidal carbon dioxide is better than arterial pressure for predicting volume responsiveness by the passive leg raising test. Intensive Care Med. 2013;39:93-100.

73. Kuiper AN, Trof RJ, Groeneveld ABJ. Mixed venous $\mathrm{O} 2$ saturation and fluid responsiveness after cardiac or major vascular surgery. J Cardiothorac Surg. 2013;8:189.

74. Klijn E, van Velzen MHN, Lima AP, Bakker J, van Bommel J, Groeneveld $A B J$. Tissue perfusion and oxygenation to monitor fluid responsiveness in critically ill, septic patients after initial resuscitation: a prospective observational study. J Clin Monit Comput. 2015 Jan 20; [Epup ahead of print]
75. Cavallaro F, Sandroni C, Marano C, La Torre G, Mannocci A, De Waure C, et al. Diagnostic accuracy of passive leg raising for prediction of fluid responsiveness in adults: systematic review and meta-analysis of clinical studies. Intensive Care Med. 2010;36:1475-83.

76. Monnet X, Osman D, Ridel C, Lamia B, Richard C, Teboul J. Predicting volume responsiveness by using the end-expiratory occlusion in mechanically ventilated intensive care unit patients. Crit Care Med. 2009;37:951-6.

77. Silva S, Jozwiak M, Teboul J, Persichini R, Richard C, Monnet X. Endexpiratory occlusion test predicts preload responsiveness independently of positive end-expiratory pressure during acute respiratory distress syndrome. Crit Care Med. 2013:41:1692-701.

78. Monnet X, Teboul JL. Assessment of volume responsiveness during mechanical ventilation: recent advances. Crit Care. 2013;17:217.

79. Guinot P-G, Godart J, de Broca B, Bernard E, Lorne E, Dupont H. Endexpiratory occlusion manoeuvre does not accurately predict fluid responsiveness in the operating theatre. Br J Anaesth. 2014;112:1050-4.

80. Geerts BF, Aarts LPHJ, Groeneveld AB, Jansen JRC. Predicting cardiac output responses to passive leg raising by a PEEP-induced increase in central venous pressure, in cardiac surgery patients. Br J Anaesth. 2011;107:150-6.

81. Wilkman E, Kuitunen A, Pettilä V, Varpula M. Fluid responsiveness predicted by elevation of PEEP in patients with septic shock. Acta Anaesthesiol Scand. 2014;58:27-35

82. Geerts BF, Maas J, de Wilde RBP, Aarts LPHJ, Jansen JRC. Arm occlusion pressure is a useful predictor of an increase in cardiac output after fluid loading following cardiac surgery. Eur J Anaesthesiol. 2011;28:802-6.

83. Muller L, Toumi M, Bousquet P-J, Riu-Poulenc B, Louart G, Candela D, et al. An increase in aortic blood flow after an infusion of $100 \mathrm{ml}$ colloid over 1 minute can predict fluid responsiveness: the mini-fluid challenge study. Anesthesiology. 2011;115:541-7.

84. Wu Y, Zhou S, Zhou Z, Liu B. A 10 second fluid challenge guided by transthoracic echocardiography can predict fluid responsiveness. Crit Care. 2014;18:R108.

85. Nouira S, Elatrous S, Dimassi S, Besbes L, Boukef R, Mohamed B, et al. Effects of norepinephrine on static and dynamic preload indicators in experimental hemorrhagic shock. Crit Care Med. 2005;33:2339-43.

86. Giraud R, Siegenthaler N, Arroyo D, Bendjelid K. Impact of epinephrine and norepinephrine on two dynamic indices in a porcine hemorrhagic shock model. J Trauma Acute Care Surg. 2014;77:564-9. quiz 650-1.

87. Suehiro K, Tanaka K, Mikawa M, Uchihara Y, Matsuyama T, Matsuura T, et al. Improved performance of the fourth-generation FloTrac/Vigileo System for tracking cardiac output changes. J Cardiothorac Vasc Anesth. 2015;29:656-62.

88. Monnet X, Jabot J, Maizel J, Richard C, Teboul J-L. Norepinephrine increases cardiac preload and reduces preload dependency assessed by passive leg raising in septic shock patients. Crit Care Med. 2011;39:689-94.

\section{Submit your next manuscript to BioMed Central and we will help you at every step:}

- We accept pre-submission inquiries

- Our selector tool helps you to find the most relevant journal

- We provide round the clock customer support

- Convenient online submission

- Thorough peer review

- Inclusion in PubMed and all major indexing services

- Maximum visibility for your research

Submit your manuscript at www.biomedcentral.com/submit
O) BioMed Central 